\title{
A DNA repair variant in POLQ (c.-1060A > G) is associated to hereditary breast cancer patients: a case-control study
}

Ana Paula Carneiro Brandalize ${ }^{1,3,4^{*}}$, Lavínia Schüler-Faccini ${ }^{2,4}$, Jean-Sébastien Hoffmann ${ }^{5,6}$, Maira Caleffi ${ }^{7}$, Christophe Cazaux ${ }^{5,6}$ and Patricia Ashton-Prolla ${ }^{1,2,4^{*}}$

\begin{abstract}
Background: One of the hallmarks of cancer is the occurrence of high levels of chromosomal rearrangements as a result of inaccurate repair of double-strand breaks (DSB). Germline mutations in BRCA and RAD51 genes, involved in DSB repair, are strongly associated with hereditary breast cancer. Pol $\theta$, a translesional DNA polymerase specialized in the replication of damaged DNA, has been also shown to contribute to DNA synthesis associated to DSB repair. It is noteworthy that POLQ is highly expressed in breast tumors and this expression is able to predict patient outcome. The objective of this study was to analyze genetic variants related to $P O L Q$ as new population biomarkers of risk in hereditary (HBC) and sporadic (SBC) breast cancer.

Methods: We analyzed through case-control study nine SNPs of POLQ in hereditary (HBC) and sporadic (SBC) breast cancer patients using Taqman Real Time PCR assays. Polymorphisms were systematically identified through the NCBI database and are located within exons or promoter regions. We recruited 204 breast cancer patients (101 SBC and 103 $\mathrm{HBC}$ ) and 212 unaffected controls residing in Southern Brazil.

Results: The rs581553 SNP located in the promoter region was strongly associated with HBC (c.-1060A > G; HBC $\mathrm{GG}=15$, Control $T=8 ; \mathrm{OR}=5.67, \mathrm{Cl} 95 \%=2.26-14.20 ; \mathrm{p}<0.0001)$. Interestingly, 11 of 15 homozygotes for this polymorphism fulfilled criteria for Hereditary Breast and Ovarian Cancer (HBOC) syndrome. Furthermore, 12 of them developed bilateral breast cancer and one had a familial history of bilateral breast cancer. This polymorphism was also associated with bilateral breast cancer in 67 patients ( $O R=9.86, \mathrm{Cl} 95 \%=3.81-25.54)$. There was no statistically significant difference of age at breast cancer diagnosis between SNP carriers and non-carriers.
\end{abstract}

Conclusions: Considering that Pol $\theta$ is involved in DBS repair, our results suggest that this polymorphism may contribute to the etiology of $\mathrm{HBC}$, particularly in patients with bilateral breast cancer.

Keywords: $P O L Q, D N A$ repair, Breast cancer, Translesional DNA polymerase, SNP

\footnotetext{
* Correspondence: anapaulabrandalize@yahoo.com.br; pprolla@gmail.com 'Laboratory of Medical Genomics, Experimental Research Center, Hospital de Clínicas de Porto Alegre, Porto Alegre, Brazil

${ }^{3}$ Laboratory of Genomics, Proteomics and DNA Repair, University of Caxias do Sul, Caxias do Sul, Brazil

${ }^{2}$ Department of Genetics, Federal University of Rio Grande do Sul, Porto Alegre, Brazil

Full list of author information is available at the end of the article
}

\section{Biomed Central}

(c) 2014 Brandalize et al.; licensee BioMed Central Ltd. This is an Open Access article distributed under the terms of the Creative Commons Attribution License (http://creativecommons.org/licenses/by/4.0), which permits unrestricted use, distribution, and reproduction in any medium, provided the original work is properly credited. The Creative Commons Public Domain Dedication waiver (http://creativecommons.org/publicdomain/zero/1.0/) applies to the data made available in this article, unless otherwise stated. 


\section{Background}

Breast cancer is the major cause of cancer death among women worldwide. Although significant progress has been made to increase our knowledge on the mechanisms of carcinogenesis in the breast, the exact steps and contribution of each of these to breast cancer development remain elusive. Among the established risk factors for breast cancer are germline mutations in two highly penetrant genes: $B R C A 1$ and BRCA2 [1,2]. These mutations strongly increase breast cancer risk by disrupting homologous recombination repair (HRR) of DNA double strand breaks (DSBs) $[3,4]$. Indeed, one of the hallmarks of cancer is the occurrence of high levels of chromosomal rearrangements as a result of inaccurate repair of DSBs [5]. Mutations in the $B R C A$ genes and other genes encoding proteins involved in DSB repair (i.e. RAD51) are mostly associated with hereditary breast cancer and increase the genetic instability caused by DSBs [6-8].

DNA polymerase theta $(\mathrm{Pol} \theta)$ is a recently identified translesional polymerase specialized in the replication of damaged DNA, which performs in vitro translesion synthesis at an AP sites and thymine glycol lesions. It is likely a major enzyme for such bypass in mammalian cells as it can perform both insertion in front of the damage and extension of the misincorporated nucleotide $[9,10]$. It is an A-family polymerase composed of 2592 amino acids encoded by POLQ (3q13.31). Its function was first identified in Drosophila, where the mutant gene MUS308 (ortholog of POLQ) was unable to survive to the chemical agents used to induce DNA breaks [11]. This polymerase possesses a unique structure with a conserved helicase domain at its $\mathrm{N}$-terminal region, a polymerase domain at the C-terminus and a long central domain [12]. The lack of 3 ' -5 ' exonuclease activity explains its low fidelity, generating substitutions at a frequency 10 to 100 times higher than observed with other family A polymerases [13].

Although the function of $\mathrm{Pol} \theta$ is not yet fully understood, several studies suggest that it may hold an important role in the maintenance of genome stability [14]. Pol $\theta$ has been proposed to be a backup DNA polymerase for base excision repair in chicken DT40 cells [15] and in nematodes $[16,17]$. A role in the repair of DSB by performing DNA synthesis during alternative microhomology-mediated endjoining has been shown in Drosophila $[18,19]$ and this potential DNA repair function may explain why mouse Pol $\theta$-deficient bone marrow and erythrocyte cells as well as human Pol $\theta$-depleted tumor cells show increased sensitivity to ionizing radiation [20,21]. It was also observed that $\operatorname{Pol} \theta$ possesses a polymerase activity in regions with DSBs [12]. In vitro studies in different organisms demonstrated that POLQ mutations resulted in abnormal DNA repair processes, decreased cell growth rates, arrest in G2 and increased chromosomal breaks and exchanges $[9,15,16,22]$.
In the context of cancer, the up-regulation of $P O L Q$ is observed in different tumor tissues, including lung, stomach, colon, breast, melanoma and oral squamous cell carcinomas [21,23-27]. Recently, the expression of 13 human DNA polymerase genes was evaluated in breast carcinomas. Among these, POLQ showed the highest level of expression. Interestingly, patients with a more aggressive phenotype of breast cancer (triple negative), also had the highest levels of POLQ expression and lower survival $(\mathrm{OR}=4.28 ; \mathrm{p}=0.0001)$, regardless of the levels of CYCLIN E and number of positive nodes [23]. These results were then confirmed in an independent cohort by Higgins et al. in $2010(\mathrm{OR}=5.80 ; \mathrm{p}=0.001)$. In addition, fibroblasts transfected with a vector containing $P O L Q$ led to replicative stress and chromosomal instability [23].

Given the importance of DNA polymerase POLQ as genetic signature for the development and progression of breast cancer, the analysis of genetic variants in the POLQ gene represents a yet poor explored field of potential biomarkers in patients with breast cancer. Taken into account the possible involvement of POLQ in single and/or DSB repair, we hypothesized that variations in this DNA repair gene could drive the development of breast cancer. Here, we evaluated the possible contribution of nine SNPs in the POLQ gene to the development of both sporadic and hereditary breast cancer through a case-control approach.

\section{Methods}

\section{Subjects}

The subjects included in this study were divided into three groups: (1) Sporadic Breast Cancer (SBC), included women diagnosed with breast cancer above age 50 years who had no family history of breast cancer or other tumors; (2) Hereditary Breast Cancer (HBC), composed by women with a positive family history of breast cancer and other tumors and whose pedigrees met criteria for at least one of the hereditary breast cancer syndromes (HBOC - Hereditary Breast and Ovarian Cancer, HBCC Hereditary Breast and Colon Cancer, SLF - Li-Fraumeni Syndrome or Li-Fraumeni like Syndrome) and excluding patients with known BRCA mutations; and (3) Patients without clinical evidence and/or suspected breast cancer participating in a mammographic screening program with normal (BIRADS 1 or 2) mammography scans within the last 12 months prior to sample collection. Along the study, a decision was made to include a fourth study group, and a cohort of 67 patients with bilateral breast cancer, regardless of age at diagnosis and family history of breast and other cancers was recruited. This study was performed independently of full BRCA1, BRCA2, TP53 and CHEK2 genotyping, based on the phenotype and clinical criteria for these syndromes. Thus, information on 
mutation status for high penetrance breast cancer genes is not available.

The study was approved by the Research Ethics Committee of Hospital de Clínicas de Porto Alegre (HCPA; protocol number 11-0328) and informed consent was obtained from all women before recruitment.

\section{SNP selection}

Nine SNPs were systematically identified through the NCBI SNP database (http://www.ncbi.nlm.nih.gov/snp). SNPs were selected based on likelihood of affecting normal protein function (Table 1), association with an amino acid change in the protein (missense mutation) and location within exons. The most informative TagSNP and polymorphisms located in the putative transcription factor binding sites were identified using S NPinfo (http://www. snpinfo.niehs.nih.gov). Missense SNPs were included in our analysis due to their possible effect on protein function. The Polyphen prediction tool was used to predict a possible impact of this substitution. The Regulome DB was used to predict the effect of 5'UTR SNPs. SNPs with minor allele frequencies (MAF) described as less than 0.1 for European population databases were excluded.

\section{Genotyping}

Peripheral blood samples collected in EDTA tubes were subjected to DNA extraction using the GE extraction kit (GE Healthcare Lifesciences BR). TaqMan assays were used for SNP genotyping. Genotypes were determined by the TaqMan probes C_88490787-10, C_86270772-10, C_88490786, C_919228-10, C_8248307-20, C_31746782-10, C_3100675-10 and C_61757736. Two custom assays were specially developed, one for the Tag SNP and another for rs11713643 (Applied Biosystems). Real-time PCR reactions were performed in 48-well plates. Briefly, each reaction contained 20ng of genomic DNA, $6.25 \mu \mathrm{l}$ of $2 \mathrm{x}$ MasterMix Genotyping TaqMan (Applied Biosystems), $0.31 \mu \mathrm{l}$ of probes specific for each polymorphism (40x) and $4.94 \mu \mathrm{l}$ of DNase-free water. A StepOne PCR Real-
Time System was used for all reactions, with an initial cycle of 10 minutes at $95^{\circ} \mathrm{C}$, followed by 45 cycles of 15 seconds at $92^{\circ} \mathrm{C}$ and 1 minute at $60^{\circ} \mathrm{C}$.

\section{Statistical analyses}

The Chi-square test was used to assess deviation from Hardy-Weinberg equilibrium and to compare allele and genotypic frequencies between cases and control groups. For each statistically significant association, an unconditional binary logistic regression model was fitted to calculate the odds ratios (ORs) and 95\% confidence intervals (CIs). Statistical analyses were performed using SPSS software version 18.0.

\section{Results}

A total of $103 \mathrm{HBC}$ and $101 \mathrm{SBC}$ patients were included in the case groups, and their clinical characteristics are summarized in Table 2. The control group included 212 women unaffected by breast cancer whose mean age was 56 years $(\mathrm{SD}=5.8$ years $)$.

The observed distribution of POLQ genotypes and allele frequencies in all groups, as well as their respective frequencies in 1000 Genomes database are shown in Table 3. Since the geographic region of patient recruitment is extensively colonized by Europeans [28], we used the expected allelic frequencies published in 1000 Genomes for euro-descendent populations as reference to minimize effects of population admixture in the analysis. Three of the nine SNPs studied (rs61757736, rs41545723, rs55748151) were not found in any of the groups. The allelic distribution for the other polymorphisms were in Hardy-Weinberg equilibrium in all groups, and the observed allele frequencies in controls are in agreement with those described for euro-descendants in the 1000 Genomes database. Overall, the POLQ genotype frequencies were equally distributed in SBC and controls with the exception of rs581553 located in the promoter region of the gene, which was strongly associated with an increased risk for $\mathrm{HBC}$ (c.-1060A > G; HBC GG = 15,

Table 1 Characteristics of selected POLQ SNPs

\begin{tabular}{|c|c|c|c|c|c|}
\hline SNP ID & Region & Protein domain & Mutation type & Aminoacid change & Possible functional effect \\
\hline rs587553 & -1060 & & & & Putative TFBS* \\
\hline rs13065220 & -190 & & & & Putative TFBS* \\
\hline rs3806614 & -323 & & & & Putative TFBS* \\
\hline rs11713643 & intron 1 & & TagSNP & & Tags 23 of 56 SNPs listed at SNP info \\
\hline rs41545723 & Exon 4 & helicase & missense & Leu197Arg & possibly damaging ${ }^{* *}$ \\
\hline rs61757736 & Exon 6 & helicase & missense & Ser305Ala & possibly damaging** \\
\hline rs55748151 & Exon 6 & helicase & missense & Val310Gly & possibly damaging** \\
\hline rs3218651 & Exon 16 & central & missense & His1201Arg & possibly damaging** \\
\hline rs1381057 & Exon 28 & polymerase & missense & Gly2513Arg & possibly damaging ${ }^{* *}$ \\
\hline
\end{tabular}

*TFBS = Transcription Binding Factor Site; Functional effect predicted by regulome DB.

${ }^{* *}$ Funciontal effect predicted by Polyphen. 
Table 2 Clinical characteristics of HBC and SBC groups

\begin{tabular}{lcccc}
\hline Characteristic & \multicolumn{3}{c}{ HBC } & SBC \\
\cline { 2 - 4 } & HBOC & HBCC & Other* & \\
\hline $\begin{array}{l}\text { Number of patients, } \\
\text { n (\%) }\end{array}$ & $77(74.8)$ & $4(3.9)$ & $22(21.4)$ & $101(100)$ \\
$\begin{array}{l}\text { Age at diagnosis, } \\
\text { mean (sd) }\end{array}$ & $45.75(11.8)$ & $47.66(3.2)$ & $41.1(10.4)$ & $56.9(5.2)$ \\
$\begin{array}{l}\text { Age at diagnosis }>50, \\
\text { n (\%) }\end{array}$ & $25(32.5)$ & 0 & $6(27.3)$ & $101(100)$ \\
$\begin{array}{l}\text { Bilateral breast cancer, } \\
\text { n (\%) }\end{array}$ & $50(74.6)$ & $3(4.5)$ & $5(7.5)$ & $9(13.4)$ \\
$\begin{array}{l}\text { Synchronic } \\
\text { Metachronic }\end{array}$ & $23(47.8)$ & $2(66.7)$ & - & $2(22.2)$ \\
Missing & $26(50.0)$ & 0 & - & $7(77.8)$ \\
\hline
\end{tabular}

*Other: Li-Fraumeni, Li-Fraumeni like or HBCC syndromes.
Control GG = 8; OR = 5.67, CI95\% = 2.26-14.20; $\mathrm{p}<0.0001$ ). Specifically rs 581553 allele $\mathrm{G}$ was associated with $\mathrm{HBC}$ as well $(\mathrm{OR}=2.33$, CI95\% $=1.57-3.47 ; \mathrm{p}<0.0001)$. Surprisingly, presence of the polymorphic allele c.3602G, localized in the central domain of Pol $\theta$ was associated with a protective effect for breast cancer in the SBC group $(\mathrm{OR}=0.59, \mathrm{CI} 95 \%=0.36-0.96 ; \mathrm{p}<0.027)$.

Based on the strong association identified between POLQ c. $-1060 \mathrm{~A}>\mathrm{G}$ (rs581553) and HBC, we carefully reviewed the clinical features of the patients with and without the polymorphic genotype c.-1060GG, in an attempt to find a clue for its possible functional role. Interestingly, 11 of the 15 GG homozygotes fulfilled criteria for HBOC syndrome. Furthermore, 12 of them had been diagnosed with bilateral breast cancer and an additional patient reported a familial history of bilateral breast cancer. To verify whether bilateral breast cancer was associated with this polymorphism we analysed rs581553 in an additional group of 67 patients with

Table 3 Genotypic and allelic frequency of selected POLQ polymorphisms in HBC, SBC and control groups

\begin{tabular}{|c|c|c|c|c|c|c|c|c|c|c|c|c|}
\hline \multirow[t]{2}{*}{ SNP ID } & \multirow[t]{2}{*}{ Genotype } & \multicolumn{2}{|c|}{ HBC } & \multicolumn{2}{|c|}{ Control } & \multirow[t]{2}{*}{$p$} & \multicolumn{2}{|c|}{ SBC } & \multicolumn{2}{|c|}{ Control } & \multirow[t]{2}{*}{$p$} & \multirow{2}{*}{$\begin{array}{c}1000 \\
\text { Genomes }\end{array}$} \\
\hline & & $n=103$ & $\%$ & $n=212$ & $\%$ & & $n=101$ & $\%$ & $n=212$ & $\%$ & & \\
\hline & AA & 48 & 46.60 & 110 & 51.89 & & 44 & 43.56 & 110 & 51.89 & & \\
\hline rs1381057 & $A G$ & 46 & 44.66 & 86 & 40.57 & & 49 & 48.51 & 86 & 40.57 & & \\
\hline \multirow[t]{3}{*}{ c.7538A > G } & GG & 9 & 8.74 & 16 & 7.55 & 0.675 & 8 & 7.92 & 16 & 7.55 & 0.372 & \\
\hline & G & 64 & 31.07 & 118 & 27.83 & 0.401 & 65 & 32.18 & 118 & 27.83 & 0.301 & 28 \\
\hline & AA & 47 & 45.63 & 142 & 66.98 & & 59 & 58.42 & 142 & 66.98 & & \\
\hline rs587553 & $A G$ & 41 & 39.81 & 62 & 29.25 & & 34 & 33.66 & 62 & 29.25 & & \\
\hline \multirow[t]{3}{*}{ C. $-1060 A>G$} & GG & 15 & 14.56 & 8 & 3.77 & $0.0001^{a}$ & 8 & 7.92 & 8 & 3.77 & 0.172 & \\
\hline & G & 71 & 34.47 & 78 & 18.40 & $0.0001^{b}$ & 50 & 24.75 & 78 & 18.40 & 0.072 & 19 \\
\hline & AA & 44 & 42.72 & 108 & 50.94 & & 44 & 43.56 & 108 & 50.94 & & \\
\hline rs13065220 & GA & 49 & 47.57 & 89 & 41.98 & & 49 & 48.51 & 89 & 41.98 & & \\
\hline \multirow[t]{3}{*}{ C. $-190 G>A$} & GG & 10 & 9.71 & 15 & 7.08 & 0.355 & 8 & 7.92 & 15 & 7.08 & 0.473 & \\
\hline & G & 69 & 33.49 & 119 & 28.07 & 0.165 & 65 & 32.18 & 119 & 28.07 & 0.303 & 28 \\
\hline & $\mathrm{CC}$ & 36 & 34.95 & 97 & 45.75 & & 39 & 38.61 & 97 & 45.75 & & \\
\hline rs3806614 & $\mathrm{CT}$ & 54 & 52.43 & 88 & 41.51 & & 48 & 47.52 & 88 & 41.51 & & \\
\hline \multirow[t]{3}{*}{ c. $-323 C>T$} & $\Pi$ & 13 & 12.62 & 27 & 12.74 & 0.153 & 14 & 13.86 & 27 & 12.74 & 0.487 & \\
\hline & $\mathrm{T}$ & 80 & 38.84 & 142 & 33.49 & 0.213 & 76 & 37.62 & 142 & 33.49 & 0.324 & 33 \\
\hline & $\mathrm{AA}$ & 70 & 67.96 & 132 & 62.26 & & 76 & 75.25 & 132 & 62.26 & & \\
\hline rs3218651 & $A G$ & 28 & 27.18 & 72 & 33.96 & & 23 & 22.77 & 72 & 33.96 & & \\
\hline \multirow[t]{2}{*}{ c. $3602 A>G$} & GG & 5 & 4.85 & 8 & 3.77 & 0.461 & 2 & 1.98 & 8 & 3.77 & 0.073 & \\
\hline & G & 38 & 18.44 & 88 & 20.75 & 0.526 & 27 & 13.37 & 88 & 20.75 & $0.027^{c}$ & 28 \\
\hline tag SNP & $\pi$ & 36 & 34.95 & 91 & 42.92 & & 48 & 47.52 & 91 & 42.92 & & \\
\hline rs11713643 & $\mathrm{TC}$ & 51 & 49.51 & 93 & 43.87 & & 38 & 37.62 & 93 & 43.87 & & \\
\hline \multirow[t]{2}{*}{ c. $2730 T>C$} & $\mathrm{CC}$ & 16 & 15.53 & 28 & 13.21 & 0.398 & 15 & 14.85 & 28 & 13.21 & 0.576 & \\
\hline & C & 83 & 40.29 & 149 & 35.14 & 0.218 & 68 & 33.66 & 149 & 35.14 & 0.788 & 36 \\
\hline
\end{tabular}

${ }^{\mathrm{a}} \mathrm{X}^{2}$ test, $\mathrm{p}<0.0001, \mathrm{OR}=5.67, \mathrm{Cl} 95 \%=2.26-14.20$.

${ }^{b} X^{2}$ test, $\mathrm{p}<0.0001, \mathrm{OR}=2.33, \mathrm{Cl} 95 \%=1.57-3.47$

${ }^{C} X^{2}$ test, $\mathrm{p}<0.027, \mathrm{OR}=0.59, \mathrm{Cl} 95 \%=0.36-0.96$. 
bilateral breast cancer and a positive family history of either breast or breast and ovarian cancer. When the genotypic frequencies were compared, a statistically significant association remained (Bilateral Breast Cancer $\mathrm{GG}=15 ; \mathrm{OR}=9.86, \mathrm{CI} 95 \%=3.81-25.54 ; \mathrm{p}<0.0001)$, as shown in Table 4. We did not observe an association between presence of $\mathrm{G}$ allele and synchronous or metachronous bilateral breast cancer $(\mathrm{p}=0.887$; data not shown). Finally, we hypothesized that the presence of this polymorphism could facilitate or promote occurrence of early onset breast cancer and analysed a group of patients with early-onset breast cancer (age at diagnosis $<40$ years) for a potential association of this SNP. No statistically significant association was found $(\mathrm{p}=0.744$; data not shown).

\section{Discussion}

Deficient DNA repair is one of the most prominent risk factors for tumor development and genetic variations in DNA repair genes have been shown to play an important role in the carcinogenesis of breast cancer. Several genes are responsible for performing DSB DNA repair, and mutations in BRCA genes explain around 30\% of all hereditary breast cancers. Some studies indicate that the occurrence of breast cancer in families with no $B R C A$ mutations, as our HBC group, could be explained by the existence of low penetrance polymorphisms in several repair genes [1,29]. Accumulating evidence has suggested a potential role for POLQ in mammalian DSB repair. POLQ deficient mice show increased sensitivity to low doses of bleomycin in their bone marrow cells [20], and the same sensitivity has been observed in human tumor cells exposed to ionizing radiation [21]. Furthermore, knockdown of $P O L Q$ in mouse lymphoma cells increases their sensitivity to etoposide [30]. All of these agents are established mutagens that produce DNA DSB. Additional evidence supporting a role of $P O L Q$ in maintaining genomic stability comes from studies in Chaos-1 mice, where a missense mutation at position 1932 of the POLQ gene, is associated with high levels of micronuclei, and increased levels of chromosome breakage. At the same time, $P O L Q$ seems to have a unique role in DSB repair that complements the recombination machinery regulated by $A T M$ in $\mathrm{HRR}$ since $P O L Q$

Table 4 Genotypic frequency of POLQ c.-1060A > G in bilateral breast cancer patients and controls

\begin{tabular}{cccccccc}
\hline SNP ID & Genotype & \multicolumn{2}{c}{ Bilateral } & & \multicolumn{2}{c}{ Control } & p \\
\cline { 3 - 4 } & & $\mathbf{n = 6 7}$ & $\mathbf{\%}$ & & $\mathbf{n = 2 1 2}$ & $\mathbf{\%}$ & \\
\hline rs587553 & AA & 27 & 40.30 & & 142 & 66.98 & \\
& AG & 25 & 37.31 & & 62 & 29.25 & \\
& GG & 15 & 22.39 & & 8 & 3.77 & $0.0001^{*}$
\end{tabular}

${ }^{*} \mathrm{X}^{2}$ test, $\mathrm{p}<0.0001, \mathrm{OR}=9.86, \mathrm{C} 195 \%=3.81-25.54$. knockout mice display enhanced chromosome instability in ATM-deficient cells [31]. The identification of the human POLQ ortholog in mus308/Drosophila as well as in mus301/spn-C, which is involved in meiotic DSBs repair and checkpoint activation [32], reinforces the potential involvement of POLQ in HRR. POLQ seems to play an additional role in DSB repair utilizing as substrate DNA by the incorporation of random nucleotide sequences [33]. Finally, the tolerance to DSB is not uniquely dependent on the polymerase activity of Pol $\theta$. The protein's helicase domain is likely involved [34]. In Drosophila, POLQ acts in this sites where its helicase activity unwinds short stretches of DSBs to expose pre-existing microhomologous sequences that are used to align the broken ends to provide a template for pol $\theta$ polymerase activity [19]. Definitely, the mechanism in which Pol $\theta$ coordinates its polymerase and helicase activities to participate in repair of different types of DNA lesions remains to be determined.

Here we showed that a specific SNP in the promoter region of $P O L Q$ is associated the phenotype of hereditary breast and ovarian cancer syndrome and/or with bilateral breast cancer, but not sporadic breast cancer. To the best of our knowledge this study is the first to demonstrate an association between a POLQ SNP and increased risk for multiple primary breast tumors. In 2008, a germline frameshift mutation, expected to disrupt the polymerase activity, was identified in one patient with a personal and familial history of breast cancer. The authors also described five missense variants in POLQ in other 38 women with SBC, but none of these variants seemed to affect gene function [2]. Recently, the effects of 11 POLQ SNPs were studied in a population-based series of 783 Swedish breast cancer patients, but no association was observed [35]. In agreement with our data, these studies did not find a strong association between $\mathrm{SBC}$ and $P O L Q$ variants probably because different mechanisms influence chromosomal instability and carcinogenesis in sporadic and hereditary breast cancers. The components of genetic susceptibility in SBC, where a highly penetrant germline mutation in a cancer predisposition gene is not identified, are still poorly understood and the environmental aetiological factors definitively contribute to increase the risk. In addition, this and other previous studies of $P O L Q$ variants are limited in sample size to identify significant associations of lower penetrance variants.

In favour of a deleterious effect of POLQ c.-1060GG, its frequency in controls was relatively low (around 3\%) as compared to the frequency in patients with $\mathrm{HBC}$ (around 15\%). It is also interesting to note that the majority $(73.3 \%)$ of patients harbouring the homozygous mutant genotype in the $\mathrm{HBC}$ group had a personal and family history consistent with HBOC. The development 
of multiple primary breast tumors (bilateral breast tumor) can be associated to disrupted $P O L Q$ expression that may be involved in DSB repair. In hereditary cancers, the presence of chromosomal instability is linked to germline mutations in genes associated with DNA DSB or interstrand cross-links repair [36]. Such mutations have been previously associated with bilateral breast cancer in several populations [37,38].

According to Regulome DB database (http://regulome. stanford.edu/index), $P O L Q$ c. $-1060 \mathrm{~A}>\mathrm{G}$ is located in a putative transcription binding factor site of Ying Yang1 protein, encoded by the $Y Y 1$ gene. This protein is a ubiquitous, conserved, multifunctional zinc-finger transcription factor that regulates initiation, activation, or repression of transcription from a variety of genes required for cell growth, development, differentiation and tumor suppression [39-42]. The DNA-binding activity of $Y Y 1$ increases dramatically early in S phase [43], where $P O L Q$ would be present to perform its translesion or repair activity. It is notyet known whether $Y Y 1$ negatively or positively regulates the expression of $P O L Q$. However, the Yin Yang 1 protein positively regulates $B R C A 1$ and inhibits breast cancer formation [41]. On the other hand, YY1-deficient spermatocytes show univalent formation, increased aneuploidy, and pachytene cell death, which are likely due to defects in DNA repair [44]. Thus, we hypothesize that the presence of $P O L Q$ c. $-1060 \mathrm{~A}>\mathrm{G}$ SNP prevents Ying Yang-1 binding to its transcription binding site, disrupting $P O L Q$ expression. This in turn disturbs or diminishes DSB repair, leading to a phenotype of increased chromosomal instability, as observed in BRCA-deficient and other hereditary breast cancer phenotypes.

\section{Conclusions}

Our data contributes to previous evidence suggesting that downregulation or absence of $P O L Q$ expression leads to inaccurate DSB repair. Thus POLQ could be considered as an important player in breast carcinogenesis, acting in this context as a tumor suppressor gene due to its important role in DNA repair. Further analysis to explain the functional consequences of $P O L Q$ c.1060GG on YY1-mediated POLQ expression and on breast cancer progression are warranted. The whole sequencing of $P O L Q$ gene and its untranslated regions would also be fundamental to determine whether these inherited genetic variations can predispose women to breast cancer, and particularly to bilateral breast cancer.

\section{Abbreviations}

DSB: Double strand breaks; HBC: Hereditary breast cancer; HBOC: Hereditary breast and ovarian cancer syndrome; HBCC: Hereditary breast and colon cancer syndrome; HCPA: Clinical hospital of porto alegre; C195\%: Confidence interval; HRR: Homologous recombination repair; MAF: Minor allele frequencies; OR: Odds ratio; PCR: Polymerase chain reaction; SBC: Sporadic breast cancer;
SLF: Li-Fraumeni syndrome or li-fraumeni like syndrome; SNP: Single nucleotide polymorphism; UTR: Untranslated region; SD: Standard deviation.

\section{Competing interests}

The authors declare that they have no competing interests.

\section{Authors' contributions}

APCB conceived the study, conducted the experiments, analysed data and wrote the manuscript. LSF, JSH and CC participated in its design, helped on the interpretation of the results and revised critically the manuscript. MC recruited and collected the clinical data of breast cancer patients. PP conceived and coordinated the study, analysed the data and helped to draft the manuscript. All authors reviewed and approved the final manuscript.

\section{Acknowledgements}

The authors would like to thank Dr. Ingrid Petroni Ewald for helping with the recruitment of the bilateral breast cancer patients and the following financial support: INAGEMP - National Institute of Population Medical Genetics (grant CNPq 573993/2008-4), CNPq (grant 484018/2013-2) and FIPE/HCPA (GPPG \#11-0328).

\section{Author details}

'Laboratory of Medical Genomics, Experimental Research Center, Hospital de Clínicas de Porto Alegre, Porto Alegre, Brazil. ${ }^{2}$ Department of Genetics, Federal University of Rio Grande do Sul, Porto Alegre, Brazil. '²aboratory of Genomics, Proteomics and DNA Repair, University of Caxias do Sul, Caxias do Sul, Brazil. ${ }^{4}$ Instituto Nacional de Genética Médica Populacional, INAGEMP, Porto Alegre, Brazil. ${ }^{5}$ Equipe « Labellisée Ligue contre le Cancer 2013 » INSERM Unit 1037; CNRS ERL 5294; CRCT (Cancer Research Center of Toulouse), Toulouse Oncopole, France. ${ }^{6}$ University of Toulouse; UPS, F-31077 Toulouse, France. ${ }^{7}$ Hospital Moinhos de Vento, Porto Alegre, Brazil.

Received: 4 February 2014 Accepted: 7 November 2014 Published: 19 November 2014

\section{References}

1. Kobayashi H, Ohno S, Sasaki Y, Matsuura M: Hereditary breast and ovarian cancer susceptibility genes (Review). Oncol Rep 2013, 30(3):1019-1029.

2. Wang X, Szabo C, Qian C, Amadio PG, Thibodeau SN, Cerhan JR, Petersen GM, Liu W, Couch FJ: Mutational analysis of thirty-two double-strand DNA break repair genes in breast and pancreatic cancers. Cancer Res 2008, 68(4):971-975.

3. Jasin M: Homologous repair of DNA damage and tumorigenesis: the BRCA connection. Oncogene 2002, 21(58):8981-8993.

4. Zhao WT, Wang YT, Huang ZW, Fang J: BRCA2 affects the efficiency of DNA double-strand break repair in response to $\mathrm{N}$-nitroso compounds with differing carcinogenic potentials. Oncol Lett 2013, 5(6):1948-1954.

5. Hanahan D, Weinberg RA: Hallmarks of cancer: the next generation. Cell 2011, 144(5):646-674.

6. Konishi H, Mohseni M, Tamaki A, Garay JP, Croessmann S, Karnan S, Ota A, Wong HY, Konishi Y, Karakas B, Tahir K, Abukhdeir AM, Gustin JP, Cidado J, Wang GM, Cosgrove D, Cochran R, Jelovac D, Higgins MJ, Arena S, Hawkins L, Lauring J, Gross AL, Heaphy CM, Hosokawa Y, Gabrielson E, Meeker AK, Visvanathan $\mathrm{K}$, Argani P, Bachman KE, et al: Mutation of a single allele of the cancer susceptibility gene BRCA1 leads to genomic instability in human breast epithelial cells. Proc Natl Acad Sci U S A 2011, 108(43):17773-17778.

7. Liu Y, West SC: Distinct functions of BRCA1 and BRCA2 in double-strand break repair. Breast Cancer Res 2002, 4(1):9-13.

8. Golmard L, Caux-Moncoutier V, Davy G, Al Ageeli E, Poirot B, Tirapo C, Michaux D, Barbaroux C, d'Enghien CD, Nicolas A, Castéra L, Sastre-Garau X, Stern $\mathrm{MH}$, Houdayer C, Stoppa-Lyonnet D: Germline mutation in the RAD51B gene confers predisposition to breast cancer. BMC Cancer 2013, 13:484.

9. Seki M, Masutani C, Yang LW, Schuffert A, Iwai S, Bahar I, Wood RD: Highefficiency bypass of DNA damage by human DNA polymerase Q. EMBO J 2004, 23(22):4484-4494.

10. Seki M, Wood RD: DNA polymerase theta (POLQ) can extend from mismatches and from bases opposite a (6-4) photoproduct. DNA Repair (Amst) 2008, 7(1):119-127. 
11. Boyd JB, Sakaguchi K, Harris PV: mus308 mutants of Drosophila exhibit hypersensitivity to DNA cross-linking agents and are defective in a deoxyribonuclease. Genetics 1990, 125(4):813-819.

12. Seki M, Marini F, Wood RD: POLQ (Pol theta), a DNA polymerase and DNA-dependent ATPase in human cells. Nucleic Acids Res 2003, 31(21):6117-6126.

13. Arana ME, Seki M, Wood RD, Rogozin IB, Kunkel TA: Low-fidelity DNA synthesis by human DNA polymerase theta. Nucleic Acids Res 2008, 36(11):3847-3856

14. Yousefzadeh MJ, Wood RD: DNA polymerase POLQ and cellular defense against DNA damage. DNA Repair (Amst) 2013, 12(1):1-9.

15. Yoshimura M, Kohzaki M, Nakamura J, Asagoshi K, Sonoda E, Hou E, Prasad R, Wilson SH, Tano K, Yasui A, Lan L, Seki M, Wood RD, Arakawa H, Buerstedde JM, Hochegger H, Okada T, Hiraoka M, Takeda S: Vertebrate POLQ and POLbeta cooperate in base excision repair of oxidative DNA damage. Mol Cell 2006, 24(1):115-125

16. Prasad R, Longley MJ, Sharief FS, Hou EW, Copeland WC, Wilson SH: Human DNA polymerase theta possesses 5'-dRP lyase activity and functions in single-nucleotide base excision repair in vitro. Nucleic Acids Res 2009 37(6):1868-1877

17. Asagoshi K, Lehmann W, Braithwaite EK, Santana-Santos L, Prasad R, Freedman $J$, Van Houten B, Wilson SH: Single-nucleotide base excision repair DNA polymerase activity in C. elegans in the absence of DNA polymerase $\beta$. Nucleic Acids Res 2012, 40(2):670-681.

18. Yu AM, McVey M: Synthesis-dependent microhomology-mediated end joining accounts for multiple types of repair junctions. Nucleic Acids Res 2010, 38(17):5706-5717.

19. Chan SH, Yu AM, McVey M: Dual roles for DNA polymerase theta in alternative end-joining repair of double-strand breaks in Drosophila. PLOS Genet 2010, 6(7):e1001005

20. Goff JP, Shields DS, Seki M, Choi S, Epperly MW, Dixon T, Wang H, Bakkenist CJ, Dertinger SD, Torous DK, Wittschieben J, Wood RD, Greenberger JS: Lack of DNA polymerase theta (POLQ) radiosensitizes bone marrow stromal cells in vitro and increases reticulocyte micronuclei after total-body irradiation. Radiat Res 2009, 172(2):165-174.

21. Higgins GS, Prevo R, Lee YF, Helleday T, Muschel RJ, Taylor S, Yoshimura M, Hickson ID, Bernhard EJ, McKenna WG: A small interfering RNA screen of genes involved in DNA repair identifies tumor-specific radiosensitization by POLQ knockdown. Cancer Res 2010, 70(7):2984-2993.

22. Muzzini DM, Plevani P, Boulton SJ, Cassata G, Marini F: Caenorhabditis elegans POLQ-1 and HEL-308 function in two distinct DNA interstrand cross-link repair pathways. DNA Repair (Amst) 2008, 7(6):941-950.

23. Lemée F, Bergoglio V, Fernandez-Vidal A, Machado-Silva A, Pillaire MJ, Bieth A, Gentil C, Baker L, Martin AL, Leduc C, Leduc C, Lam E, Magdeleine E, Filleron T, Oumouhou N, Kaina B, Seki M, Grimal F, Lacroix-Triki M, Thompson A, Roché H, Bourdon JC, Wood RD, Hoffmann JS, Cazaux C: DNA polymerase theta up-regulation is associated with poor survival in breast cancer, perturbs DNA replication, and promotes genetic instability. Proc Natl Acad Sci U S A 2010, 107(30):13390-13395.

24. Pillaire MJ, Selves J, Gordien K, Gourraud PA, Gouraud PA, Gentil C, Danjoux M, Do C, Negre V, Bieth A, Guimbaud R, Trouche D, Pasero P, Méchali M, Hoffmann JS, Cazaux C: A 'DNA replication' signature of progression and negative outcome in colorectal cancer. Oncogene 2010, 29(6):876-887.

25. Lessa RC, Campos AH, de Freitas CE, da Silva FR, Kowalski LP, Carvalho AL, Vettore AL: Identification of upregulated genes in oral squamous cell carcinomas. Head Neck 2012, 35(10):1475-1481.

26. Allera-Moreau C, Rouquette I, Lepage B, Oumouhou N, Walschaerts M, Leconte E, Schilling V, Gordien K, Brouchet L, Delisle MB, Honda I, Sakiyama S, Tagawa M, O-Wang J: DNA replication stress response involving PLK1, CDC6, POLQ, RAD51 and CLASPIN upregulation prognoses the outcome of early/mid-stage non-small cell lung cancer patients. Oncogenesis 2012, 1:e30.

27. Kawamura K, Bahar R, Seimiya M, Chiyo M, Wada A, Okada S, Hatano M, Tokuhisa T, Kimura H, Watanabe S, Honda I, Sakiyama S, Tagawa M, O-Wang J: DNA polymerase theta is preferentially expressed in lymphoid tissues and upregulated in human cancers. Int J Cancer 2004, 109(1):9-16.

28. Paskulin DD, Cunha-Filho JS, Souza CA, Bortolini MC, Hainaut P, Ashton-Prolla P: TP53 PIN3 and PEX4 polymorphisms and infertility associated with endometriosis or with post-in vitro fertilization implantation failure. Cell Death Dis 2012, 3:e392.

29. Matta J, Echenique M, Negron E, Morales L, Vargas W, Gaetan FS, Lizardi ER, Torres A, Rosado JO, Bolaños G, Cruz JG, Laboy J, Barnes R, Medina SS,
Romero A, Martinez R, Dutil J, Suarez E, Alvarez-Garriga C, Bayona M: The association of DNA repair with breast cancer risk in women. A comparative observational study. BMC Cancer 2012, 12:490.

30. Ukai A, Maruyama T, Mochizuki S, Ouchida R, Masuda K, Kawamura K, Tagawa M, Kinoshita K, Sakamoto A, Tokuhisa T, O-Wang J: Role of DNA polymerase theta in tolerance of endogenous and exogenous DNA damage in mouse B cells. Genes Cells 2006, 11(2):111-121.

31. Shima N, Munroe RJ, Schimenti JC: The mouse genomic instability mutation chaos 1 is an allele of Polq that exhibits genetic interaction with Atm. Mol Cell Biol 2004, 24(23):10381-10389.

32. Laurencon A, Orme CM, Peters HK, Boulton CL, Vladar EK, Langley SA, Bakis EP, Harris DT, Harris NJ, Wayson SM, Hawley RS, Burtis KC: A large-scale screen for mutagen-sensitive loci in Drosophila. Genetics 2004, 167(1):217-231.

33. Hogg M, Seki M, Wood RD, Doublié S, Wallace SS: Lesion bypass activity of DNA polymerase $\theta$ (POLQ) is an intrinsic property of the pol domain and depends on unique sequence inserts. J Mol Biol 2011, 405(3):642-652.

34. Li Y, Gao X, Wang JY: Comparison of two POLQ mutants reveals that a polymerase-inactive POLQ retains significant function in tolerance to etoposide and $\gamma$-irradiation in mouse B cells. Genes Cells 2011, 16(9):973-983.

35. Varadi V, Bevier M, Grzybowska E, Johansson R, Enquist K, Henriksson R, Butkiewicz D, Pamula-Pilat J, Tecza K, Hemminki K, Lenner P, Försti A: Genetic variation in genes encoding for polymerase $\zeta$ subunits associates with breast cancer risk, tumour characteristics and survival. Breast Cancer Res Treat 2011, 129(1):235-245.

36. Deniz M, Holzmann $\mathrm{K}$, Wiesmüller L: Functional analysis-make or break for cancer predictability. Mutat Res 2013, 743-744:132-141.

37. Kato M, Yano K, Matsuo F, Saito H, Katagiri T, Kurumizaka H, Yoshimoto M, Kasumi F, Akiyama F, Sakamoto G, Nagawa H, Nakamura Y, Miki Y: Identification of Rad51 alteration in patients with bilateral breast cancer. J Hum Genet 2000, 45(3):133-137.

38. Garcia-Casado Z, Romero I, Fernandez-Serra A, Rubio L, Llopis F, Garcia A, Llombart P, Lopez-Guerrero JA: A de novo complete BRCA1 gene deletion identified in a Spanish woman with early bilateral breast cancer. BMC Med Genet 2011, 12:134.

39. Kassardjian A, Rizkallah R, Riman S, Renfro SH, Alexander KE, Hurt MM: The transcription factor $Y Y 1$ is a novel substrate for Aurora B kinase at G2/M transition of the cell cycle. PLoS One 2012, 7(11):e50645.

40. Hwang SS, Kim YU, Lee S, Jang SW, Kim MK, Koh BH, Lee W, Kim J, Souabni A, Busslinger M, Lee GR: Transcription factor YY1 is essential for regulation of the Th2 cytokine locus and for Th2 cell differentiation. ProC Natl Acad Sci U S A 2013, 110(1):276-281.

41. Lee MH, Lahusen T, Wang RH, Xiao C, Xu X, Hwang YS, He WW, Shi Y, Deng CX: Yin Yang 1 positively regulates BRCA1 and inhibits mammary cancer formation. Oncogene 2012, 31(1):116-127.

42. Wu S, Kasim V, Kano MR, Tanaka S, Ohba S, Miura Y, Miyata K, Liu X Matsuhashi A, Chung UI, Yang L, Kataoka K, Nishiyama N, Miyagishi M: Transcription factor YY1 contributes to tumor growth by stabilizing hypoxia factor HIF-1a in a p53-independent manner. Cancer Res 2013, 73(6):1787-1799

43. Palko L, Bass HW, Beyrouthy MJ, Hurt MM: The Yin Yang-1 (YY1) protein undergoes a DNA-replication-associated switch in localization from the cytoplasm to the nucleus at the onset of S phase. J Cell Sci 2004, 117(Pt 3):465-476.

44. Wu S, Hu YC, Liu H, Shi Y: Loss of YY1 impacts the heterochromatic state and meiotic double-strand breaks during mouse spermatogenesis. $\mathrm{Mol}$ Cell Biol 2009, 29(23):6245-6256.

doi:10.1186/1471-2407-14-850

Cite this article as: Brandalize et al: A DNA repair variant in POLQ (c.-1060A > G) is associated to hereditary breast cancer patients: a case-control study. BMC Cancer 2014 14:850. 